\title{
Identifying the stabilising regions of PI controller based on frequency specifications for a lab scale distillation column
}

\section{R. Janani}

Department of Electronics and Instrumentation Engineering, Sri Chandrasekharendra Saraswathi Viswa Mahavidyalaya, Enathur, Kanchipuram-631561, Tamilnadu, India

Email: janurang@gmail.com

\section{Vinayambika S. Bhat}

Department of Electronics and Communication Engineering, Mangalore Institute of Technology and Engineering, Moodabidri-574225, Karnataka, India

Email: vinayambika09@gmail.com

\section{Indiran Thirunavukkarasu* and V.I. George}

Department of Instrumentation and Control Engineering,

Manipal Institute of Technology,

Manipal Academy of Higher Education,

Manipal-576104, Karnataka, India

Email: it.arasu@manipal.edu

Email: vi.george@manipal.edu

*Corresponding author

\begin{abstract}
The aim of the study is to design and implement decentralised PI controller for a lab scale distillation column based on the frequency specifications. Designing an effective PI controller for an MIMO process is a challenging task because of the loop interaction and system with dead time. In order to eliminate these interactions between the control loops, an ideal decoupling technique is implemented and first order plus dead time model is obtained for each decoupled subsystems. By plotting the boundary locus for each subsystems based on the desired gain and phase margin in $\left(k_{p}, k_{i}\right)$ plane a wide range of PI values are obtained. Also, the performance measurement calculations were compared and tabulated for various values of $k_{p}$ and $k_{i}$ with the boundary locus. In this present research the pressure and temperature near the bottom of the column is considered. It is also shown that the system become unstable when the value of PI controller is selected outside the boundary locus.
\end{abstract}

Keywords: boundary locus; decentralised controller; gain margin; phase margin.

Reference to this paper should be made as follows: Janani, R., Bhat, V.S., Thirunavukkarasu, I. and George, V.I. (2020) 'Identifying the stabilising regions of PI controller based on frequency specifications for a lab scale distillation column', Int. J. Digital Signals and Smart Systems, Vol. 4, Nos. 1/2/3, pp.1-16. 
Biographical notes: R. Janani is working as an Assistant Professor in Electronics and Instrumentation Engineering at Sri Chandrasekharendra Saraswathi Viswa Mahavidyalaya, Kanchipuram. She received her BE degree from Madras University in 2004 and MTech degree from SASTRA Deemed to be University of Advanced Communication Systems in 2006 and pursuing his $\mathrm{PhD}$ degree. She is a member in IAENG. Her interest is in the research areas of process control, robust control and advanced control engineering.

Vinayambika S. Bhat is working as a Senior Assistant Professor in Electronics and Communication Engineering at Mangalore Institute of Technology and Engineering, Mangalore. She received her BE degree from Malnad College of Engineering in 2004 and MTech degree from NMAMIT, Nitte and $\mathrm{PhD}$ degree from Manipal Institute of Technology, Manipal. Her interest includes advanced control engineering, and robust control engineering.

Indiran Thirunavukkarasu is currently working as an Associate Professor (Sr. Scale) from the Department of Instrumentation and Control Engineering, Manipal Institute of Technology, Manipal Academy Higher Education, Manipal. He is a senior member of IEEE, and life member of SSI, ISSE, AMIE and ISTE. His research interests include process control, robust control and optimal control.

V.I. George is working as a Professor from the Department of Instrumentation and Control Engineering, Manipal Institute of Technology, Manipal Academy Higher Education, Manipal. He is a senior member of IEEE, and Fellow of ISSE. His research interests include control systems, optimisation, robust control and aerospace control.

This paper is a revised and expanded version of a paper entitled 'Identifying the stabilising regions of PI controller based on frequency specifications for a lab scale distillation column' presented at International Conference on Sustainable Energy, Electronics and Computing Systems (SEEMS-2018), Greater Noida-India, 26-27 October 2018.

\section{Introduction}

In the work on tuning of PI, PID controllers has been extensive since these types of controllers have been widely used in industries for several decades (Tan, 2005). Most of the processes in industry are multi-input and multi-output systems (MIMO). Due to the interactions in control loops, MIMO system control is quite complex compared to SISO systems (Tan et al., 2006). MIMO systems controller can be either centralised or decentralised. A better method is the decentralised PI controller with decoupler, where a decoupler is designed to deal with interactions and then a set of values $\left(k_{p}\right.$ and $\left.k_{i}\right)$ are designed using the locus of the boundary of stability. The main reason for this popularity is that PI controllers are frequently effective and easy to implement. Decentralised PI control is one of the most common control systems in the chemical and process industries for the interaction of multiple-input MIMO plants (Tavakoli et al., 2006). Margins of gain and phase served as important robustness measures and also served as a performance measure (Hamamci and Tan, 2016). The notation of gain and phase margin can be generalised for MIMO systems using unique values of the loop transfer function matrix. In this current research on a pilot plant binary distillation column, an ideal decoupler plus 
decentralised PI controller based on the frequency specification is simulated and implemented.

The distillation column is widely used for separating chemical components into more or less pure product streams in the chemical and petroleum industries. This separation is based on differences between various chemical components in volatilities. Components are removed from the top of the column in a distillation column the more volatile or lighter, and the less volatile or heavier components are removed from the lower part of the column. A mixture of isopropyl alcohol and water in the ratio of $30 \%$ and $70 \%$ for distillation is considered in the present research. The reflux flow rate (L) is measured as the LPH and the reboiler power rate (Q) is measured as the manipulated variable (MV) in $\mathrm{KW}$, whereas the controlled variable $(\mathrm{PV})$ is the pressure $(\mathrm{PB})$ and temperature in tray 1 (T1). The article uses MATLAB/Simulink software to present control algorithm simulation with and without load disturbance. The control algorithm is further validated on the PC-based Instrumentation Lab, Department of ICE, MIT, Manipal experimental setup. Further the performance indices such as integral absolute error (IAE), integral square error (ISE), integral time absolute error (ITAE) and integral square time error (ISTE) are tabulated for both servo and regulatory.

Section 2 provides a brief summary of the method of decoupler design, while Section 3 outlines the design of stabilising PI controller using the method of boundary locus. Section 4 details the column pressure mathematical modelling. The results of the PI controller's simulation and implementation based on the locus of the stability boundary are presented. The performance of the closed loop was analysed and compared within the admissible set of PI values for different PI controller values is presented in Section 5, followed by the conclusions in Section 6.

\section{Decoupler design}

One of the popular approaches to eliminate or minimise the control loop interactions is designing a decoupler is suggested by Gagnon et al. (1998). Decoupler decomposes a MIMO process into independent single loop sub-systems. Figure 1 shows the block diagram of this structure (Vijula and Devarajan, 2014). Considering the MIMO processes is given as:

$$
G(s)=\left[\begin{array}{ll}
G_{11} & G_{12} \\
G_{21} & G_{22}
\end{array}\right]
$$

where $G_{i j}=g_{i j}(s) e^{-\tau_{i j} s}, i, j=1,2$ for a TITO process. Let the $G(s)$ off-diagonal elements have no RHP poles and the $G(s)$ diagonal elements have no RHP zeros then the matrix of the decoupler is as follows:

$$
D(s)=\left[\begin{array}{cc}
1 & \frac{-G_{12}(s)}{G_{11}(s)} \\
\frac{-G_{21}(s)}{G_{22}(s)} & 1
\end{array}\right]
$$

The overall open loop transfer function of process with decoupler is given by: 


$$
Q(s)=G(s) * D(s)
$$

Once the $Q(s)$ diagonal elements, i.e., $q_{11}(s)$ and $q_{22}(s)$ are approximated in the first order plus dead time (FOPDT) model is given as (Hu et al., 2011):

$$
q_{n n}(s)=\frac{K_{p} e^{-\tau_{d} s}}{T s+1}
$$

where $K_{p}, \tau_{d}$ and $T$ are process gain, delay time and time constant respectively.

Figure 1 Block diagram of MIMO system with decoupler

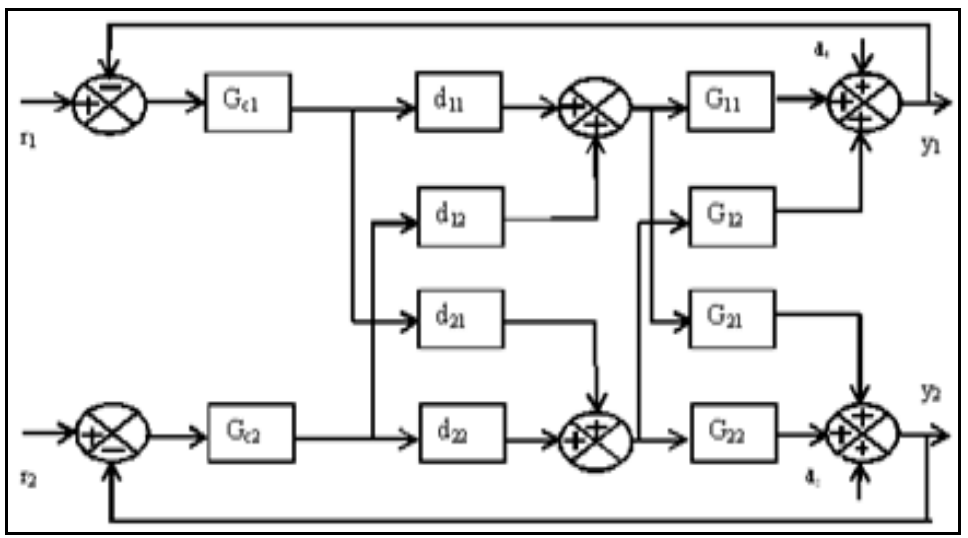

\section{Design of stabilising PI controllers}

Consider the loop transfer function of the process with decoupler $q_{i i}(s)$ to be controlled by the PI controller $K_{c i i}(s)$ where $i=1,2$ then:

$$
\begin{aligned}
& q_{i i}(s)=\frac{N_{i i}(s)}{D_{i i}(s)} e^{-\theta_{i i} s} \\
& K_{c i i}(s)=k_{p i i}+\frac{k_{I i i}}{s}
\end{aligned}
$$

where $k_{p}$ and $k_{i}$ are the tuning parameters of the PI controller (Manabe, 1998). Decomposing the numerator and the denominator polynomials of equation (4) into their even and odd parts, and substituting $s=j \omega$ gives:

$$
q_{i i}(j \omega)=\frac{N_{e}\left(-\omega^{2}\right)+j \omega N_{0}\left(-\omega^{2}\right)}{D_{e}\left(-\omega^{2}\right)+j \omega D_{0}\left(-\omega^{2}\right)}
$$

The closed loop characteristic polynomial of the system can be written as:

$$
\begin{aligned}
\Delta(s) & =\left[\left(k_{i} N_{e}-k_{p} \omega^{2} N_{o}\right) \cos (\omega \theta)+\omega\left(k_{p} N_{e}+k_{i} N_{o}\right) \sin (\omega \theta)-\omega^{2} D_{o}\right] \\
& +j\left[\omega\left(k_{p} N_{e}+k_{i} N_{o}\right) \cos (\omega \theta)-\left(k_{i} N_{e}-k_{p} \omega^{2} N_{o}\right) \sin (\omega \theta)+\omega D_{e}\right]=0
\end{aligned}
$$


Equating the real and imaginary parts of $\Delta(s)$ to zero

$$
\begin{aligned}
& k_{p}\left(-\omega^{2} N_{o} \cos (\omega \theta)+\omega N_{e} \sin (\omega \theta)\right)+k_{i}\left(N_{e} \cos (\omega \theta)+\omega N_{o} \sin (\omega \theta)\right)=\omega^{2} D_{0} \\
& k_{p}\left(\omega N_{e} \cos (\omega \theta)+\omega^{2} N_{o} \sin (\omega \theta)\right)+k_{i}\left(\omega N_{o} \cos (\omega \theta)-N_{e} \sin (\omega \theta)\right)=\omega D_{e}
\end{aligned}
$$

Solving equaiton (8) for $k_{p}$ and $k_{i}$

$$
\begin{aligned}
& k_{p}=\frac{\left(\omega^{2} N_{o} D_{o}+N_{e} D_{e}\right) \cos (\omega \theta+\varphi)+\omega\left(N_{0} D_{e}-N_{e} D_{o}\right) \sin (\omega \theta+\varphi)}{-A *\left(N_{w}^{2}+\omega^{2} N_{o}^{2}\right)} \\
& k_{i}=\frac{\omega^{2}\left(N_{o} D_{e}-N_{e} D_{o}\right) \cos (\omega \theta+\varphi)-\omega\left(N_{e} D_{e}+\omega^{2} N_{o} D_{o}\right) \sin (\omega \theta+\varphi)}{-A *\left(N_{e}^{2}+\omega^{2} N_{o}^{2}\right)}
\end{aligned}
$$

The stability boundary locus in the $\left(k_{p}, k_{i}\right)$ plane can be obtained using equations (9)-(10) (Senthilkumar and Lincon, 2012). It is observed that the stability boundary locus depends on the frequency $(\omega)$, gain margin $(A)$ and phase margin $(\varphi)$. The gain and phase margin are two important frequency domain performance measures (Ho et al., 1995).

\section{Modelling of column pressure}

The valid linear model is determined by experimentation with the open loop, which is achieved by introducing incremental change in the heater power and reflux flow rate of the reboiler and then recording the pressure developed in the column near the bottom tray. As a MV, the reflux flow rate and the reboiler power rate are used. Column modelling is classified as basic modelling, empirical modelling, and gray box modelling. Most process industries rely on empirical modelling to identify the model based on experimental data collection analysis.

Empirical modelling method reduces the deviation between the model and data between root-mean-square. The input-output relationships in this empirical model are based on the data obtained by the open loop test. The response is optimised through the leapfrogging optimisation technique, which uses all the $N$ data points to fit the model and rejects noise and disturbance. This method uses nonlinear regression and provides the FOPTD model coefficient based on the best match between the model and the experimental plant output (Vinayambika et al., 2017).

$$
\text { FOPDT model is } \frac{-0.633}{0.665 s+1} e^{-0.0252 s}
$$

The reflux flow rate $\mathrm{L}\left(u_{1}\right)$ and reboiler power rate $\mathrm{Q}\left(u_{2}\right)$ was used as MV. Bottom tray temperature $\mathrm{T}\left(T_{1}\right)$ and pressure $\mathrm{P}\left(P_{1}\right)$ were the control variables and that were recorded. Experimentation with the open loop is performed to determine the column pressure model. In order to identify the model, the open loop response is considered by keeping constant reflux at $20 \%$ and giving the heater a step change from $50 \%$ to $80 \%$ and determining the pressure developed in the column. The second step is to keep the heater constant at $70 \%$ and to change the reflux step from $40 \%$ to $70 \%$ and to determine the pressure induced within the column. Figures 2-3 show the appropriate experimental response and the appropriate model response. 
Figure 2 Experimental data and model fit of bottom pressure to a step of 30\% in reflux (pressure transmitter is in the range of $0-0.5$ bar) (see online version for colours)

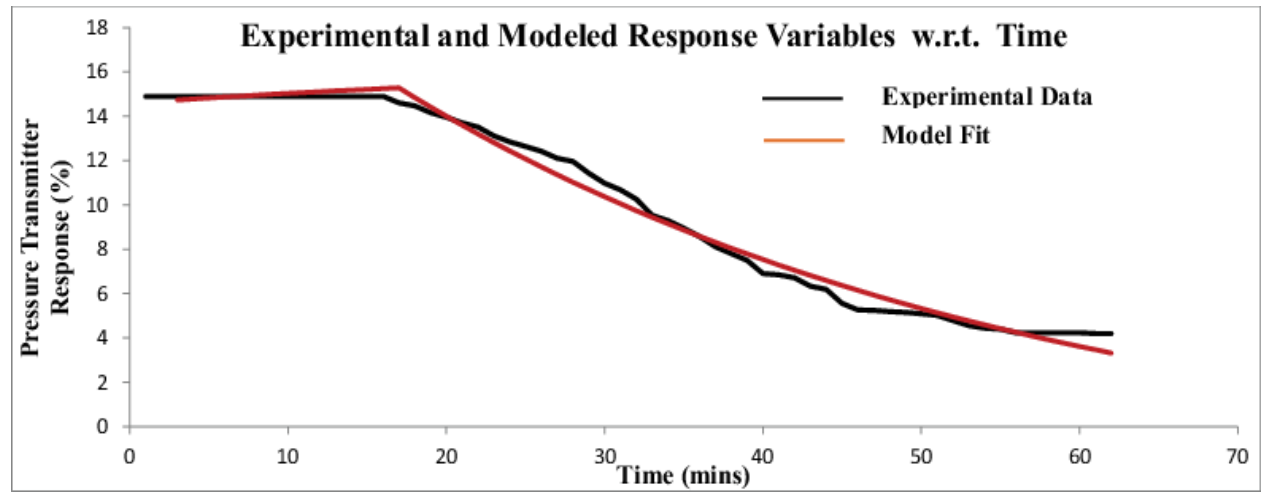

Figure 3 Experimental data and model fit of bottom pressure to a step of 30\% in reboiler heater (see online version for colours)

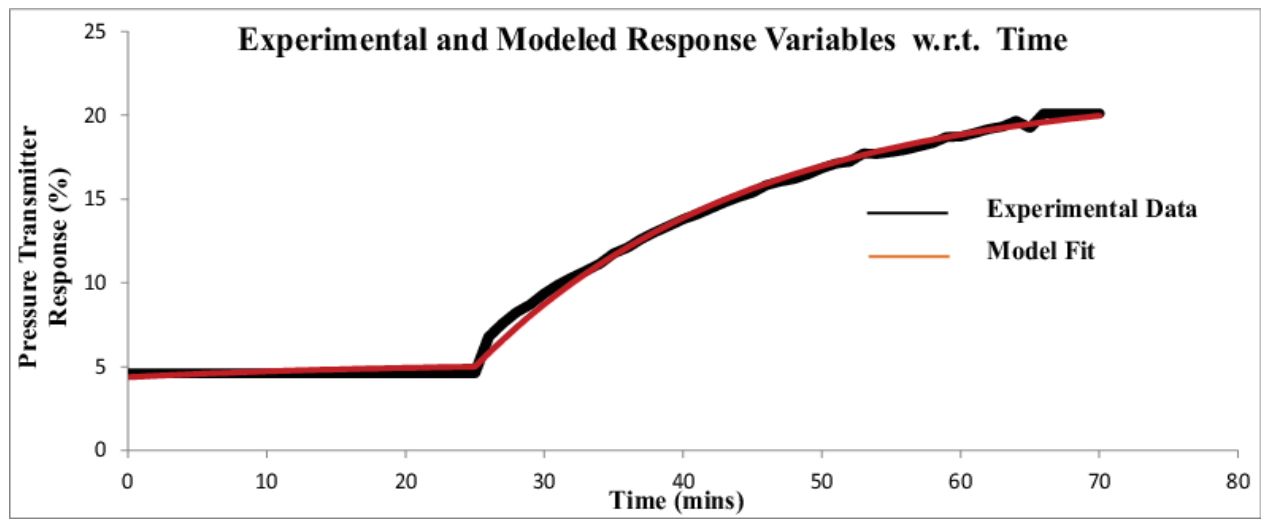

FOPDT model is $\frac{0.547}{0.328 s+1} e^{-0.007 s}$

\section{Simulation results and discussion}

The mathematical model for the top and bottom tray temperature of the pilot plant distillation column is (Vinayambika et al., 2017):

$$
G(s)=\left[\begin{array}{cc}
\frac{-0.13 e^{-0.03 s}}{1.14 s+1} & \frac{0.18 e^{-0.03 s}}{0.64 s+1} \\
\frac{-0.34 e^{-1.22 s}}{1.23 s+1} & \frac{0.18 e^{-0.03 s}}{0.32 s+1}
\end{array}\right]
$$

The bottom tray temperature and pressure are considered as process variable in the current research. The step change is applied to the reflux and heater, the time-related regression curve for the output response is obtained across the tray temperature and 
downward pressure. For simulation studies, the model identified as $2 * 2$ square systems was considered. Then, the bottom tray temperature FOPDT model from equation (11) and the bottom pressure FOPDT model considered from Section 4.

$$
\begin{aligned}
& Y(s)=G(s) u(s) \\
& {\left[\begin{array}{l}
Y_{1}(s) \\
Y_{2}(s)
\end{array}\right]=\left[\begin{array}{l}
P_{1}(s) \\
T_{1}(s)
\end{array}\right]\left[\begin{array}{l}
u_{1}(s) \\
u_{2}(s)
\end{array}\right]=\left[\begin{array}{l}
L \\
Q
\end{array}\right]} \\
& G(s)=\left[\begin{array}{cc}
\frac{-0.633 e^{-0.0252 s}}{0.665 s+1} & \frac{0.547 e^{-0.007 s}}{0.328 s+1} \\
\frac{-0.34 e^{-1.22 s}}{1.23 s+1} & \frac{0.18 e^{-0.03 s}}{0.32 s+1}
\end{array}\right]
\end{aligned}
$$

The decoupler is:

$$
D(s)=\left[\begin{array}{cc}
1 & \frac{0.5745 s+0.864}{0.328 s+1} \\
\frac{(0.6048 s+1.89) e^{-1.19 s}}{1.23 s+1} & e^{-0.0182 s}
\end{array}\right]
$$

The diagonal elements of open loop transfer function of the process are obtained as:

$$
\begin{aligned}
& q_{11}=\frac{0.40 e^{-2.29 s}}{1.314 s+1} \\
& q_{2}=\frac{-0.113 e^{-1.858 s}}{1.128 s+1}
\end{aligned}
$$

The loop transfer function from equation (14) can be decomposed into numerator and denominator terms (Thirunavukkarasu et al., 2019). By equating the real and imaginary terms of the system's characteristic polynomial to zero, we can obtain the frequencydependent boundary stability locus in plane $\left(k_{p}, k_{i}\right)$ as:

$$
\begin{aligned}
& k_{p 11}=0.82125 \omega \sin (2.29 \omega)-0.625 \cos (2.29 \omega) \\
& k_{i 11}=-0.82125 \omega^{2} \cos (2.29 \omega)+0.625 \omega \sin (2.29 \omega) \\
& k_{p 22}=2.188 \cos (1.858 \omega)-2.469 \omega \sin (1.858 \omega) \\
& k_{i 22}=-2.469 \omega^{2} \cos (1.858 \omega)-2.188 \omega \sin (1.858 \omega)
\end{aligned}
$$

A permissible set of PI controllers can be obtained from the boundary stability locus as shown in Figure 5. And, the equations (15)-(16) used for the desired gain margin and phase margin range from 3 to 8 and phase margin from 30 degree to 60 degree respectively. Figures 6-11 show the closed loop servo and regulatory response to the process transfer function model for the set of PI controllers. Table 1 shows the allowable set of PI values on the boundary locus. Tables 2-3 provide a comparison analysis of the performance indices obtained from the boundary stability locus region for the allowable set of PI controllers. Figure 12 show the systems closed loop performance when the PI controller value is beyond the locus of boundary stability. 
Table 1 Admissible set of PI controllers

\begin{tabular}{|c|c|c|c|c|}
\hline \multirow{2}{*}{ Case } & \multicolumn{2}{|c|}{ Loop 1} & \multicolumn{2}{|c|}{ Loop 2} \\
\hline & $K_{p}$ & $K_{i}$ & $K_{p}$ & $K_{i}$ \\
\hline 1 & 0.03593 & 0.1699 & -0.003116 & -1.41 \\
\hline 2 & 0.4102 & 0.2095 & -0.1835 & -1.493 \\
\hline 3 & 0.2926 & 0.276 & -0.2261 & -1.021 \\
\hline 4 & 0.5271 & 0.405 & -0.3595 & -1.567 \\
\hline
\end{tabular}

Figure 4 Lab scale binary distillation column setup (see online version for colours)

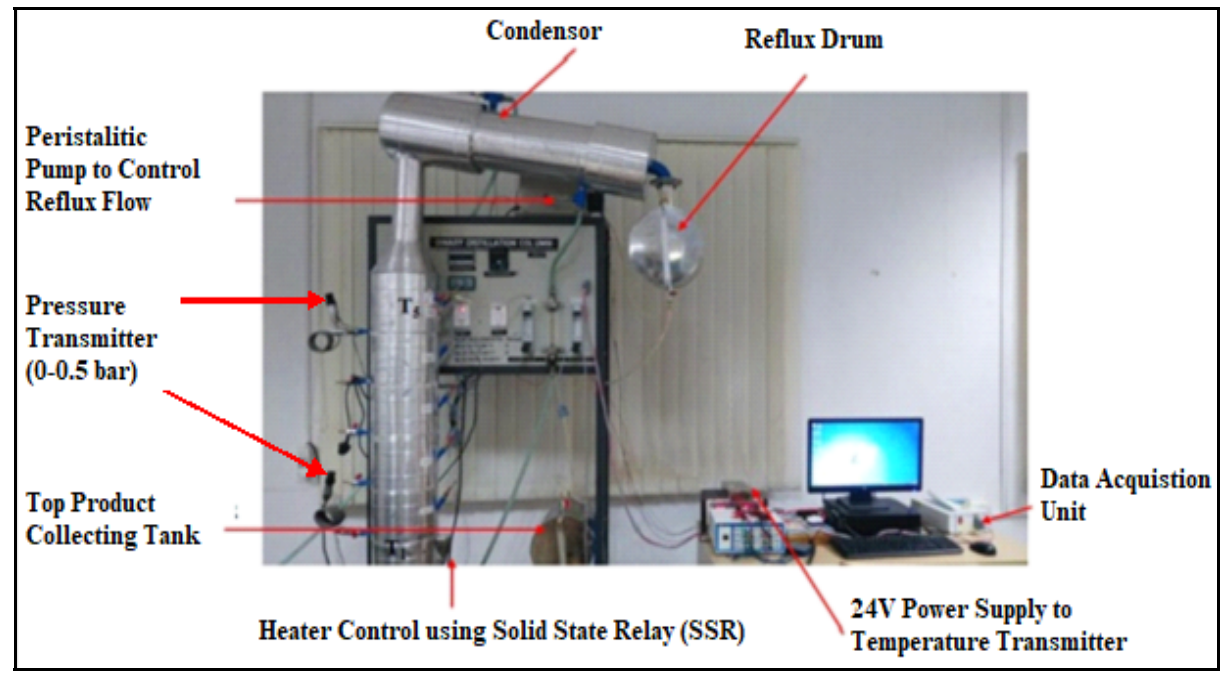

Table 2 Comparison of performance index for servo response

\begin{tabular}{|c|c|c|c|c|c|c|}
\hline \multirow{2}{*}{ Case } & \multicolumn{3}{|c|}{$I A E$} & \multicolumn{3}{|c|}{$I S E$} \\
\hline & $Y_{1}$ & $Y_{2}$ & $\sum\left(Y_{1}+Y_{2}\right)$ & $Y_{I}$ & $Y_{2}$ & $\sum\left(Y_{1}+Y_{2}\right)$ \\
\hline 1 & 14.9 & 10.3 & 25.241 & 10.60 & 19.57 & 30.174 \\
\hline 2 & 12.1 & 10.3 & 22.448 & 8.348 & 12.02 & 20.373 \\
\hline 3 & 9.19 & 9.04 & 18.232 & 7.803 & 8.255 & 16.058 \\
\hline 4 & 7.80 & 8.30 & 16.108 & 7.509 & 9.128 & 16.637 \\
\hline \multirow{2}{*}{ Case } & \multicolumn{3}{|c|}{ ITAE } & \multicolumn{3}{|c|}{ ISTE } \\
\hline & $Y_{1}$ & $Y_{2}$ & $\sum\left(Y_{1}+Y_{2}\right)$ & $Y_{1}$ & $Y_{2}$ & $\sum\left(Y_{1}+Y_{2}\right)$ \\
\hline 1 & 144.67 & 212.4 & 357.15 & 60.85 & 92.56 & 153.4 \\
\hline 2 & 105.27 & 67.59 & 172.86 & 35.24 & 37.16 & 72.4 \\
\hline 3 & 45.681 & 42.95 & 88.631 & 24.68 & 30.41 & 55.097 \\
\hline 4 & 20.867 & 67.23 & 88.097 & 15.64 & 27.87 & 43.511 \\
\hline
\end{tabular}


Table 3 Comparison of performance index for regulatory response

\begin{tabular}{lccccccc}
\hline \multirow{2}{*}{ Case } & \multicolumn{3}{c}{$I A E$} & & \multicolumn{3}{c}{$I S E$} \\
\cline { 2 - 3 } \cline { 6 - 8 } & $Y_{I}$ & $Y_{2}$ & $\sum\left(Y_{1}+Y_{2}\right)$ & & $Y_{I}$ & $Y_{2}$ & $\sum\left(Y_{1}+Y_{2}\right)$ \\
\hline 1 & 14.9 & 10.3 & 25.25 & & 10.6 & 8.97 & 19.57 \\
2 & 12.1 & 10.3 & 22.46 & & 8.34 & 9.026 & 17.366 \\
3 & 9.19 & 9.04 & 18.237 & & 7.80 & 8.256 & 16.056 \\
4 & 6.86 & 10.3 & 17.18 & & 7.50 & 9.13 & 16.63 \\
1 & 144.71 & 68.05 & 212.76 & & 60.85 & 31.75 & 92.6 \\
2 & 105.2 & 67.88 & 173.08 & & 35.23 & 31.20 & 66.43 \\
3 & 45.68 & 42.26 & 87.94 & & 24.68 & 27.41 & 52.09 \\
4 & 20.86 & 67.70 & 88.56 & & 15.64 & 30.91 & 46.55 \\
\hline
\end{tabular}

Figure 5 Boundary stability locus for loop function (see online version for colours)

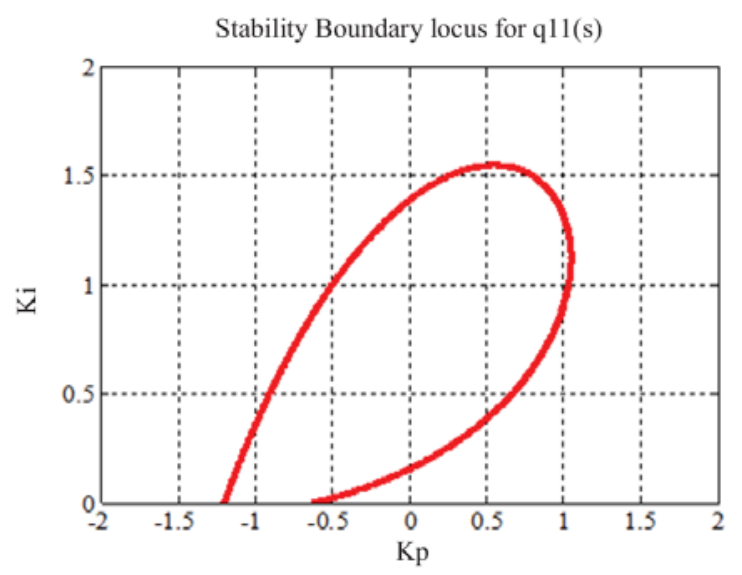

(a)

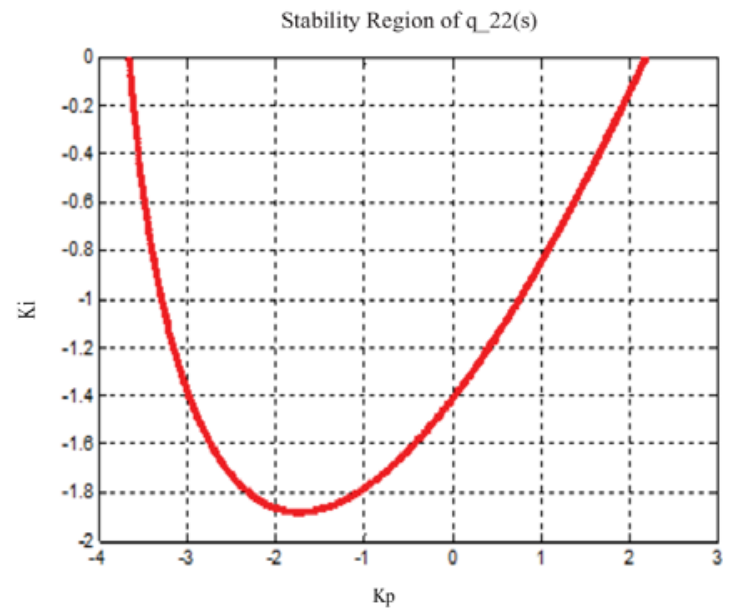

(b) 
Figure 6 Servo response of $Y_{1}$ when input $r_{1}=1$ and $r_{2}=0$ (see online version for colours)

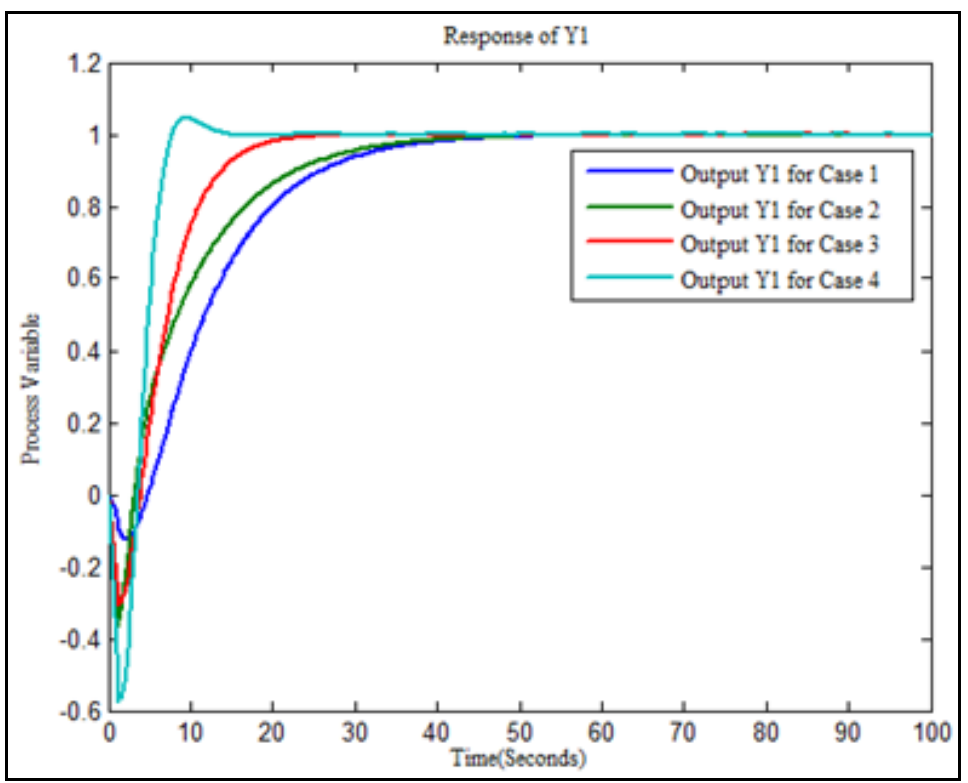

Figure 7 Servo response of $Y_{2}$ when input $r_{1}=1$ and $r_{2}=0$ (see online version for colours)

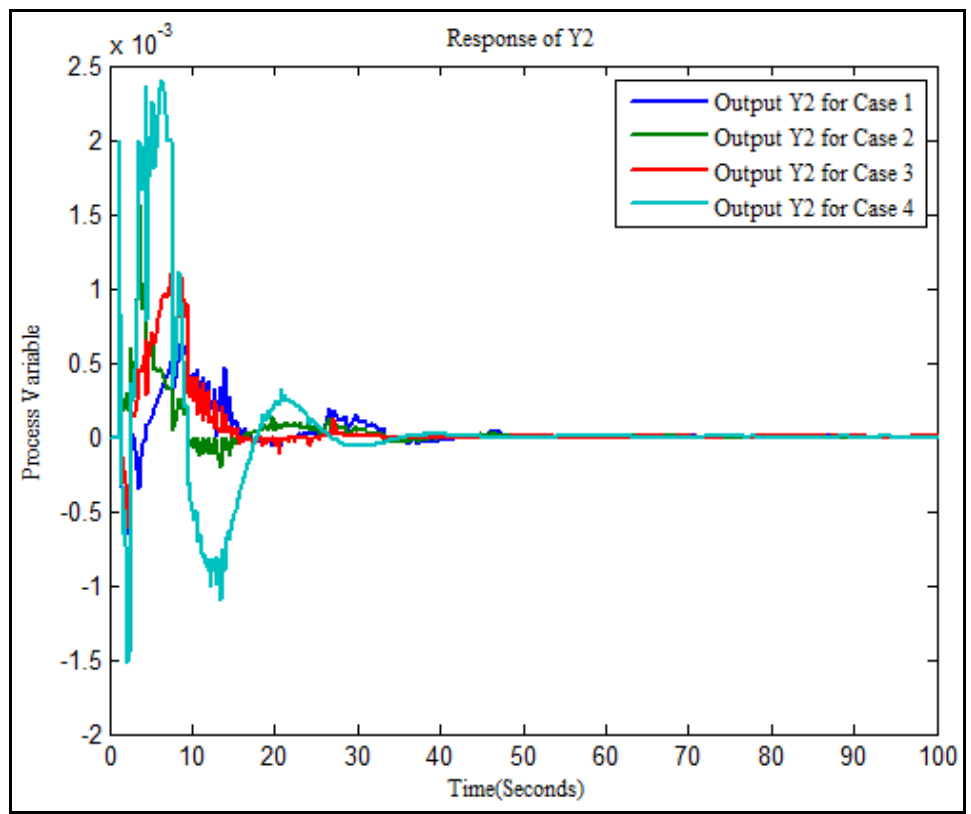


Figure 8 Servo response of $Y_{1}$ when input $r_{1}=0$ and $r_{2}=1$ (see online version for colours)

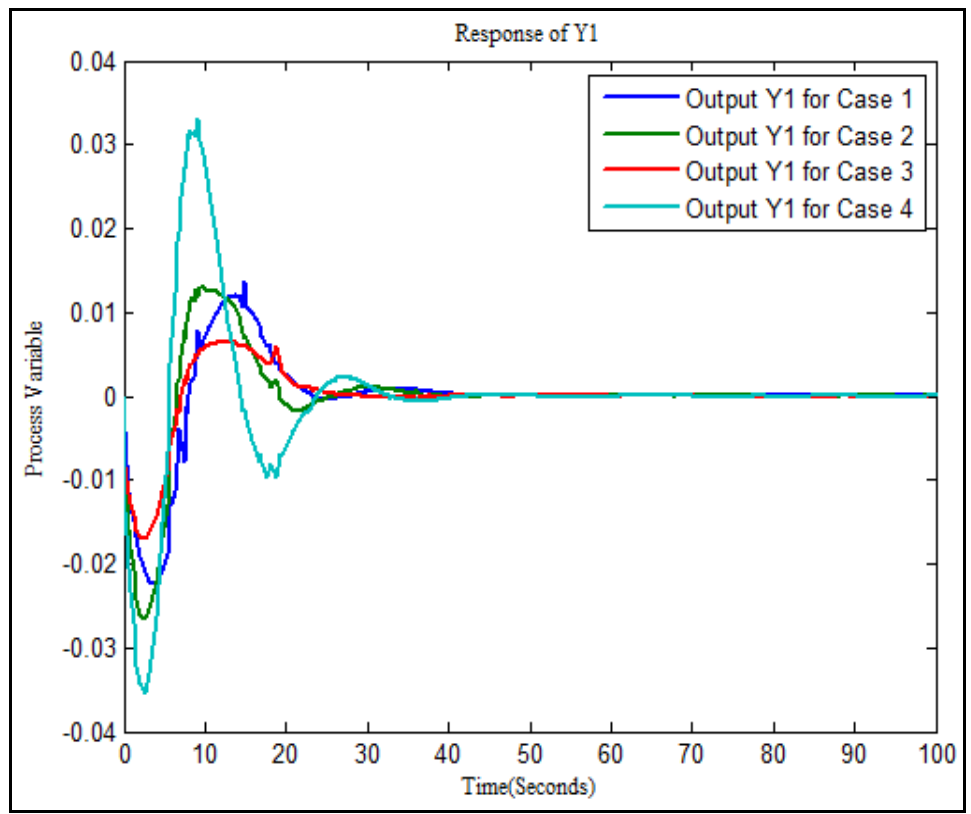

Figure 9 Servo response of $Y_{2}$ when input $r_{1}=0$ and $r_{2}=1$ (see online version for colours)

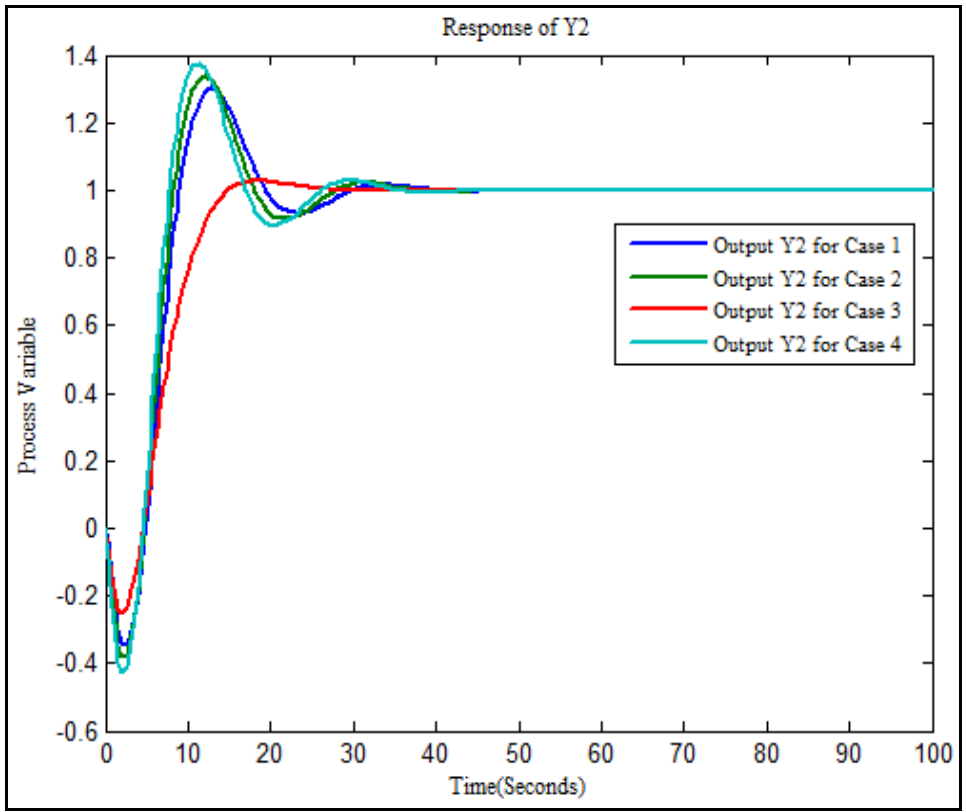


Figure 10 Regulatory response of $Y_{1}$ and $Y_{2}$ when load $1=1$ and load $2=0$ (see online version for colours)

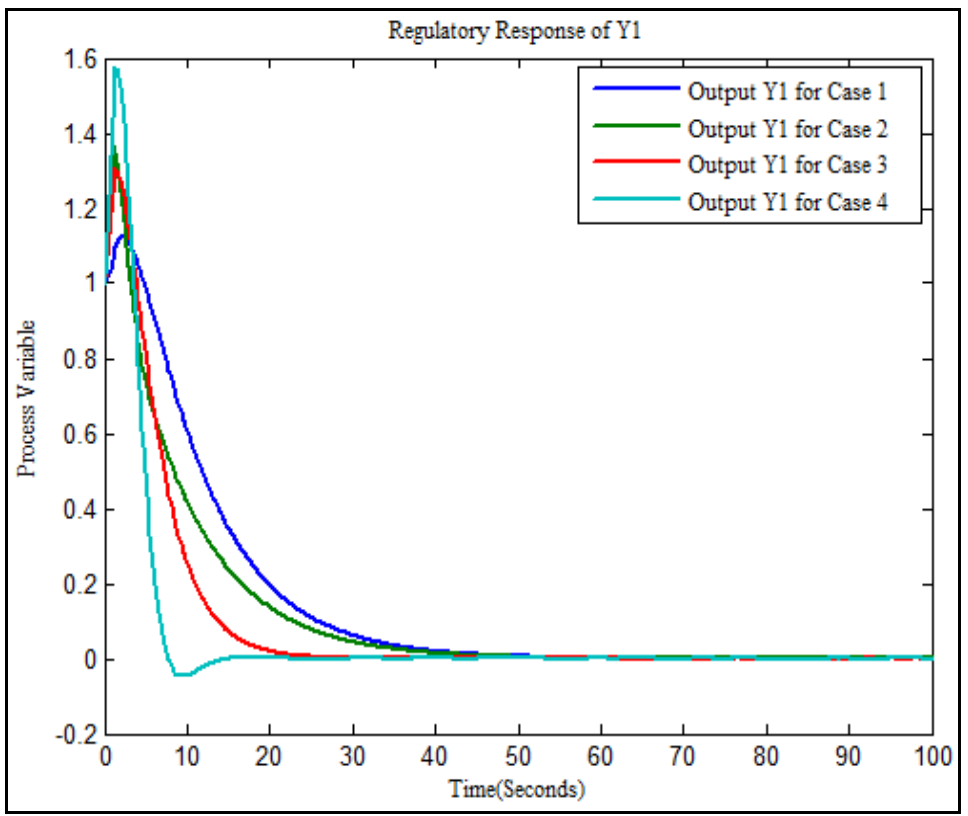

(a)

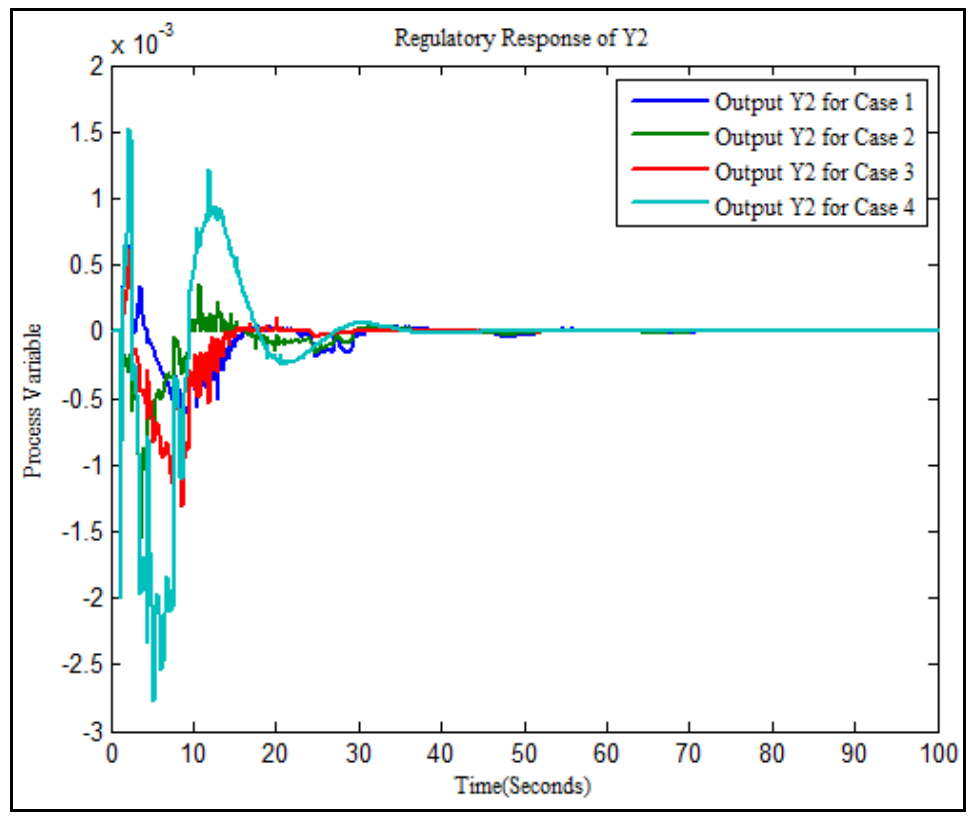

(b) 
Figure 11 Regulatory response of $Y_{1}$ and $Y_{2}$ when load $1=0$ and load $2=1$ (see online version for colours)

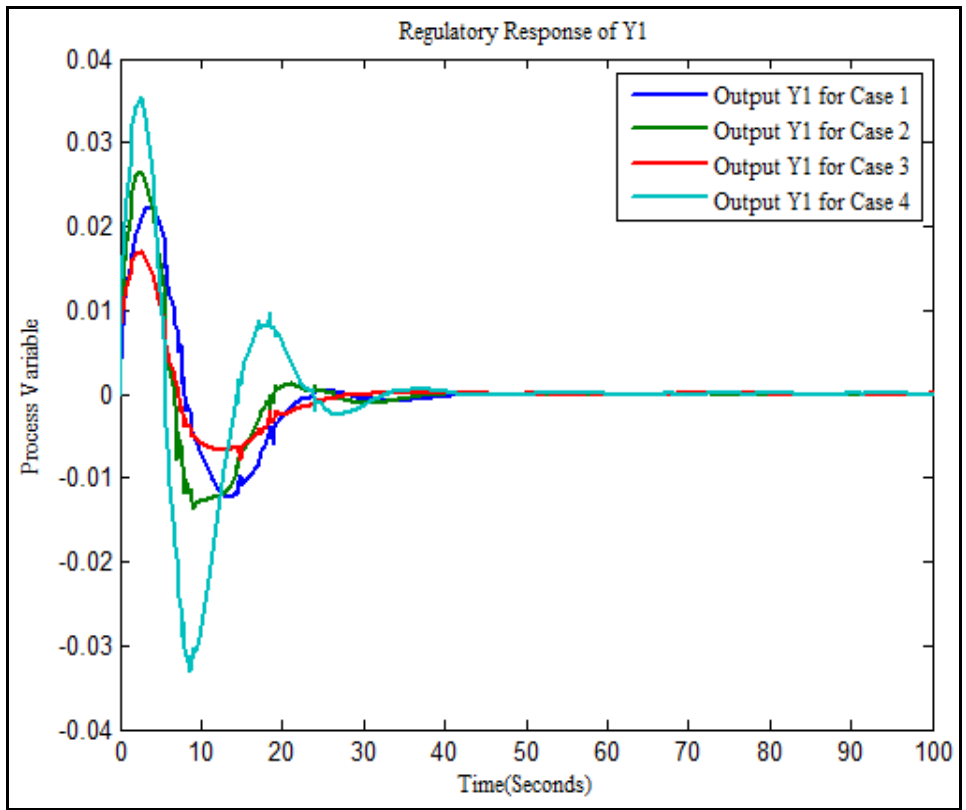

(a)

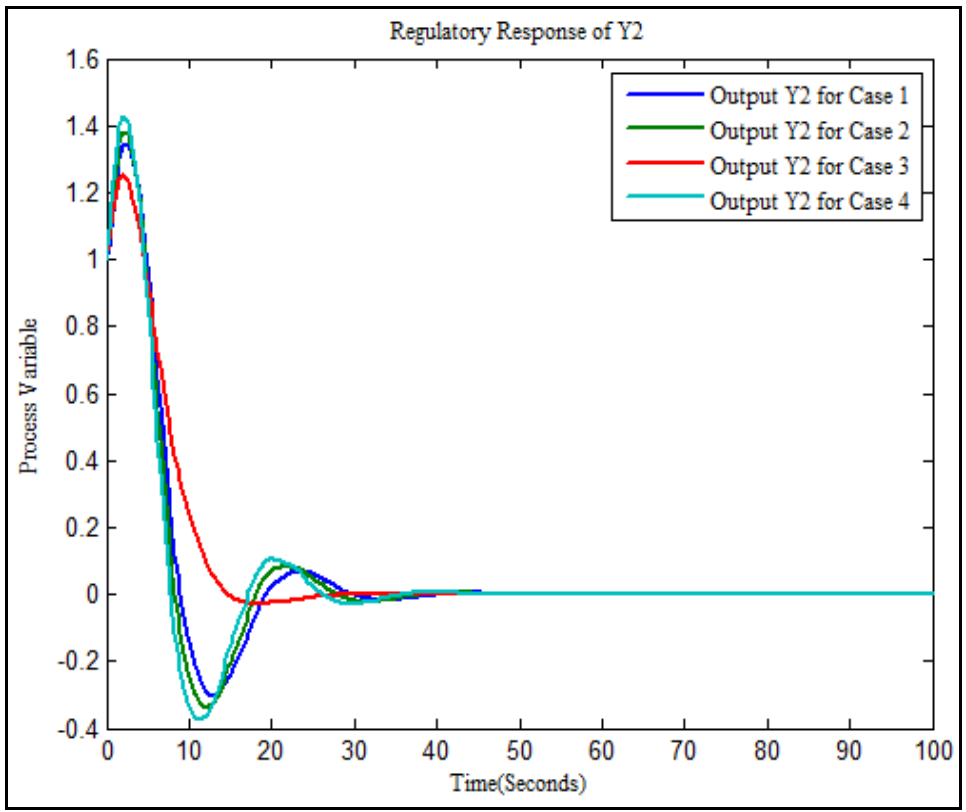

(b) 
Figure 12 Servo response of $Y_{1}$ and $Y_{2}$ when PI value selected outside the boundary locus (see online version for colours)

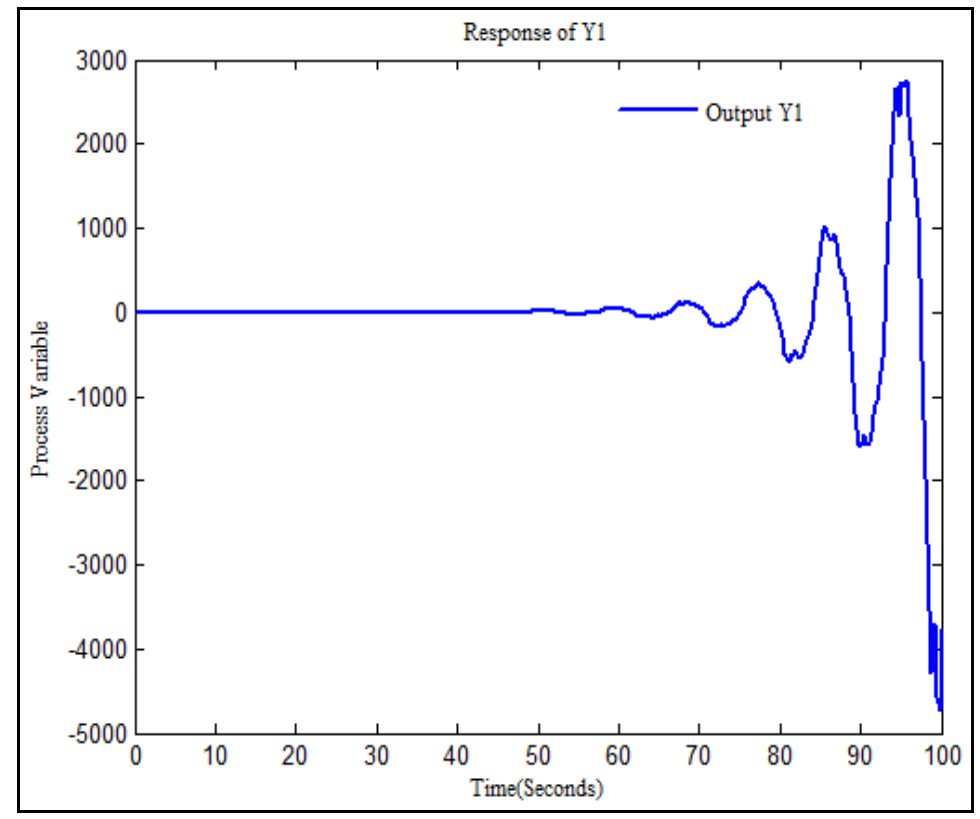

(a)

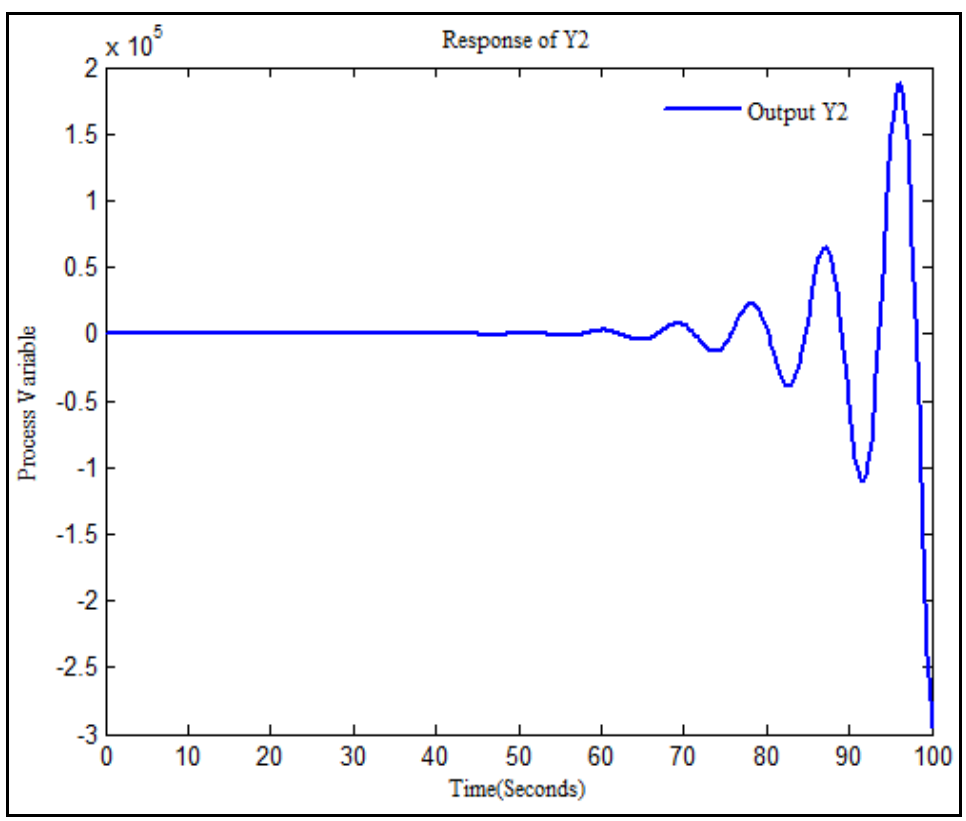

(b) 
Figure 13 Real time implementation of PI controller for temperature and pressure control in pilot plant binary distillation column (see online version for colours)

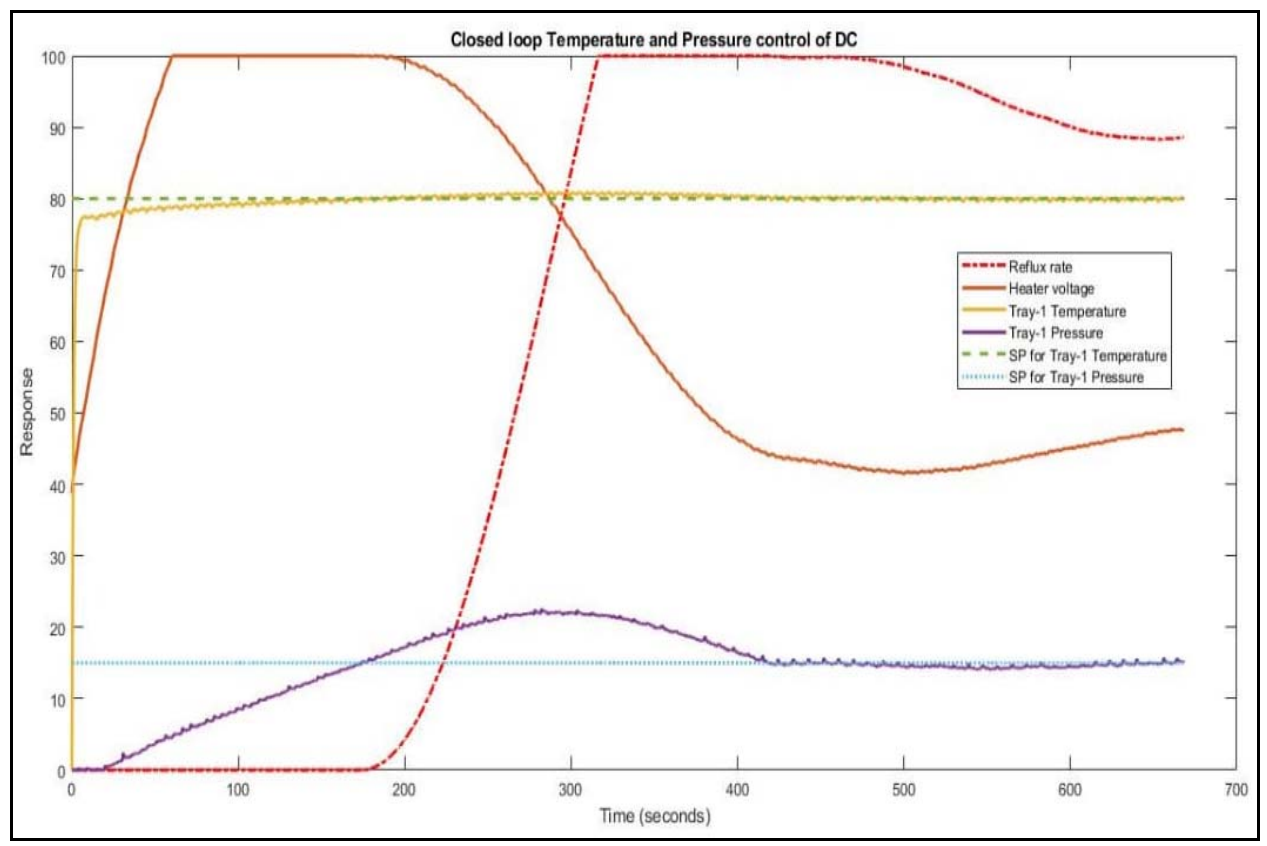

\section{Conclusions}

The PI controller based on the boundary stability locus is designed, simulated and implemented to control binary distillation column tray temperature and pressure. After applying decoupling to zero, the PI controller is designed to equate the real and imaginary part of the characteristic equation of both the loop. The controller value is obtained by plotting in $\left(K_{p}, K_{i}\right)$ plane the stability boundary locus. For the controller obtained, the simulation studies show good servo tracking and regulatory response. The real-time experimentation was also carried out following the simulation. It was observed that when the value of the PI controller is selected outside the boundary locus, the system reaches the unstable state. For the simulation model of the distillation column transfer function, the servo and regulatory responses are presented. This work can be extended to non-square process as well as stirred tank reactor.

\section{References}

Gagnon, E., Pomerleau, A. and Desbiens, A. (1998) 'Simplified, ideal or inverted decoupling', ISA Transactions, Vol. 37, No. 4, pp.265-276.

Hamamci, S.E. and Tan, N. (2016) 'Design of PI controllers for achieving time and frequency domain specification simultaneously', ISA Transaction, Vol. 45, pp.529-543.

Ho, W.K., Hang, C.C. and Cao, L.S. (1995), 'Tuning of PID controllers based on gain and phase margins specifications', Automatica, Vol. 31, No. 3, pp.497-502. 
Hu, Z-R., Li, D-H., Wang, J. and Xue, F. (2011) 'Analytical design of PID decoupling control for TITO processes with time delays', Journal of Computers, Vol. 6, No. 6, pp.1064-1070.

Manabe, S. (1998) 'Coefficient diagram method', Proceedings of the 14th IFAC symposium on Automatic Control in Aerospace, Vol. 31, No. 21, pp.211-222.

Senthilkumar, M. and Lincon, S.A. (2012) 'Design of stabilizing PI controller for coupled tank MIMO', International Journal of Engineering Research and Development, Vol. 3, No. 10, pp.47-55.

Tan, N. (2005) 'Computation of stabilizing PI and PID controllers for processes with time delay', ISA Transaction, Vol. 44, No. 2, pp.213-223.

Tan, N., Kaya, I., Yeroglu, C. and Atherton, D.P. (2006) 'Computation of stabilizing PI and PID controllers using the stability boundary locus', Energy Conversion and Management, Vol. 47, No. 18 , pp.3045-3058.

Tavakoli, S., Griffin, I. and Fleming, P.J. (2006) 'Tuning of decentralized PI (PID) controllers for TITO processes', Control Engineering Practice, Vol. 14, No. 1, pp. 1069-1080.

Thirunavukkarasu, I., Janani, R., Yadav, E. and Selvanathan, S.P. (2019) 'Modeling and control of tray temperature along with column pressure in a pilot plant distillation column', presented in IEEE International Conference on Automation, Computational and Technology Management (ICACTM-2019), Amity University London.

Vijula, D.A. and Devarajan, N. (2014) 'Decentralized PI controller design for a nonlinear multivariable systems based on ideal decoupler', International Journal of Theoretical and Applied Information Technology, Vol. 64, No. 2, pp.568-574.

Vinayambika, S., Bhat, S., Priya, S., Thirunavukkarasu, I. and Rhinehart, R.R. (2017) 'Local transient model of a pilot plant distillation response', International Journal of Pure and Applied Mathematics, Vol. 114, No. 11, pp. 277-287. 